\title{
JUURNAL.RU
}

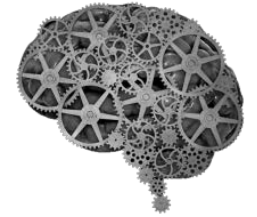

COMPANY GROUP "INTELLEKT"

Тимченко А.С., Трошкина Г.Н., Юдинцев А.Ю. ФГБОУ ВО Алтайский государственный университет Барнаул, Россия

doi: 10.18411/lj2016-8-1-11

idsp 000001:lj2016-17-1-11

\section{Модель системы мониторинга ИВС центров обработки данных в органах государственного и муниципального управления на примере территориального органа федеральной службы государственной статистики по алтайскому краю}

Качество государственных и муниципальных услуг в значительной степени зависит от эффективности работы федеральных органов исполнительной власти, органов исполнительной власти субъектов Российской Федерации и органов местног самоуправления. Использование информационнотелекоммуникационных технологий является одним из важнейших способов повышения эффективности работы указанных органов.

10 октября 2015 года опубликовано распоряжение Правительства РФ об утверждении концепции перевода обработки и хранения государственных информационных ресурсов, не содержащих сведения, составляющие государственную тайну, в систему федеральных и региональных центров обработки данных (утверждена распоряжением Правительства РФ от 7 октября 2015 г. N 1995-р). Проект концепции подготовило Министерство связи и массовых коммуникаций Российской Федерации (Минкомсвязи России).

Главная цель данной концепции - это создание системы ЦОД в виде сети федеральных и региональных центров, связанных резервированными магистральными каналами связи с высокой пропускной способностью в единый катастрофоустойчивый кластер. Трафик этого кластера не будет выходить за пределы Российской Федерации.

Планируется, что до 2021 года пользователями системы ЦОД станут федеральные и региональные государственные органы, государственные 
организации и органы местного самоуправления.

Построение системы ЦОД в России позволит федеральным органам исполнительной власти, органам исполнительной власти субъектов Российской Федерации и органов местного самоуправления организациям не задумываться о вопросах обеспечения работоспособности физического оборудования и установки программного обеспечения (ПО), а использовать ИТ технологии исключительно как инструмент для решения собственных задач. Не удивительно, что при этом будут предъявляться самые высокие требования к отказоустойчивости систем.

В такой ситуации большое значение приобретает задача реализации процесса эффективного комплексного мониторинга всех систем каждого ЦОД данной системы.

В данной работе будет рассмотрена проблема мониторинга оборудования и программного обеспечения, которые в комплексе будут составлять информационно-вычислительную сеть (ИВС) каждого ЦОД, а именно:

- Серверное оборудование;

- Сетевое оборудование (коммутаторы, маршрутизаторы и т.д.);

- Источники бесперебойного питания, которые обслуживают серверное и сетевое оборудование;

- Сервисы и/или услуги, которые будут предоставляться ИВС ЦОД.

Задача мониторинга ИВС не может быть решена без четкого анализа существующих систем мониторинга, как российских, так и зарубежных производителей. Анализ различных источников показал, что единого подхода к созданию комплекса мониторингаИВС ЦОД на данный момент - нет.

Технологически ЦОД - это специализированное здание, помещение (площадка) для размещения серверного, телекоммуникационного и коммуникационного оборудования и обеспечивающих инженерных систем, подключенное к корпоративным и/или глобальным каналам связи. ЦОД обеспечивает гарантированное бесперебойное питание размещаемого оборудования (даже при отказе внешнего энергоснабжения), выполнение требований по климатическим параметрам (температура, влажность) и безопасности (технической и информационной).

Структура ЦОДа содержит в себе функциональные элементы, предназначенные для выполнения определенных задач работы центра обработки 
данных.

«TelecommunicationsInfrastructureStandardforDataCenter» («Стандарт на телекоммуникационную инфраструктуру центров обработки данных») определены следующие структурные элементы ЦОД:

- Машинный зал - помещение (помещения) предназначенные для размещения вычислительного оборудования ЦОД. Это основное помещение (помещения) ЦОД, определяющее его функциональное предназначение. Все остальные структурные элементы (размещаемые в машинном зале или в отдельных помещениях) обеспечивают работу вычислительного оборудования и соблюдение комплекса условий его функционирования;

- Телекоммуникационные

узлы, телекоммуникационная инфраструктура - структурные элементы, обеспечивающие передачу информации между вычислительным оборудованием. В их состав входят: узлы ввода кабельной инфраструктуры, коммутационные узлы, телекоммуникационная кабельная инфраструктура;

$\checkmark$ Узлы ввода кабельной инфраструктуры предназначены для обеспечения информационного взаимодействия и доступа к вычислительному оборудованию извне, посредством информационных каналов провайдеров;

$\checkmark$ Коммутационные узлы предназначены для осуществления коммутации (соединения/переключения) информационных каналов между вычислительным оборудованием. В их состав входит активное сетевое оборудование, обеспечивающее переключение информационных каналов, и пассивное коммутационное оборудование в составе патч-панелей (или информационных розеток) и информационных кабелей;

$\checkmark$ Телекоммуникационная кабельная инфраструктура;

- Электрическое и механическое оборудование технической поддержки ЦОД (инженерная инфраструктура ЦОД) обеспечивают жизнедеятельность ЦОД. Сюда входят:

$\checkmark$ система пожарной сигнализации и пожаротушения; 
$\checkmark$ система охранной сигнализации, видеонаблюдения и контроля доступа;

$\checkmark$ система закладных и кабельных каналов;

$\checkmark$ система бесперебойного электроснабжения;

$\checkmark$ система гарантированного электроснабжения;

$\checkmark$ система общего электроснабжения;

$\checkmark$ система электрического освещения (рабочего, аварийного и эвакуационного);

$\checkmark$ система вентиляции и кондиционирования.

- Помещения операторов, которые предназначены для размещения рабочих мест обслуживающего персонала, отслеживающего сигналы систем мониторинга и осуществляющего эксплуатацию ЦОД.

- Складские помещения ЦОД, они предназначены для размещения запасных частей оборудования инженерных систем, расходных материалов, а также распаковки вновь устанавливаемого оборудования.

В большинстве организаций специалистысчитают необходимым построение централизованногомониторинга ИВС, которая должна им помогать в их работе. Действительно, тяжело одновременно следить за работой серверов, коммутаторов и прочих устройств, программного обеспечения, которые составляют ИВС. Некоторые из них имеют встроенные средства удаленного мониторинга и даже управления. К другим приходится приобретать дополнительное оборудование (платы управления) и/или дополнительное ПО. Плохо, если устройствоили ПО не имеет встроенного мониторинга,и нет возможности получить его другими способами. Эксплуатация устройства или ПО, которое не может предоставить информацию о своем состоянии, некоторые специалисты считают не допустимым.

Часто наблюдается следующая ситуация: на каждом устройстве или системе используется своя отдельная система мониторинга, со свойственными данному устройству или системе настройками. Однако, индивидуальное слежение за каждым из них не позволяет оценить ситуацию комплексно, а держать одновременно несколько запущенных программ попросту неудобно. Гораздо лучше использовать централизованные системы мониторинга. Эти системы должны обеспечить постоянное 24/7 наблюдение в реальном времени за 
инфраструктурой в поисках медленных или неисправных систем для своевременного оповещения о проблемах, сбора и предоставления данных для их дальнейшего анализа, ведения подробной статистики, что в результате позволяет выявить узкие места и сбойные участки в инфраструктуре.

Единая централизованная автоматизированная система управления инженерными системами ЦОДпозволит:

- уменьшить количество обслуживающего персонала;

- повысить надежность работы систем - исключить человеческий фактор;

- оптимизировать работу наиболее ресурсоемких сервисов;

- увеличить эффективность работы отдельных устройствза счет оптимальной загрузки оборудования;

- увеличить ресурс работы серверногои сетевого оборудования;

- гарантировать непрерывность предоставляемых услуг и сервисов;

- контролироватькачество предоставляемых услуг и сервисов.

Организация централизованной системы мониторинга ЦОД требует определенных финансовых вложений, но эти затраты обоснованы. Они несравнимо меньше издержек на ремонт оборудования. Убытки, которые может понести организация в случае ненадлежащей эксплуатации (рискуя при этом своим имиджем и репутацией), по многим показателям существенно выше сумм вложений на создание системы мониторинга. Ввод в эксплуатацию данной системы позволит нивелировать ошибки, вызванные человеческим фактором, так как алгоритм работы системы мониторинга учитывает только необходимые входные данные и посылает соответствующие сигналы управления.

Рассмотрим модель системы мониторинга ИВС ЦОД. С практической точки зрения основные требования к системе мониторинга можно сформировать в таком виде:

- наличие удобного интерфейса, желательно через веб-интерфейс, это даст возможность пользоваться различными операционными системами администраторам и операторам;

- поддержка оборудования, произведенного разными компаниями;

- поддержка разныхоперационных систем (OC): Windows, Linux и др.; 
- возможность масштабируемости и подключения нескольких пользователей к системе мониторинга;

- работа в сетях любого размера и топологии;

- способность опрашивать программную и аппаратную часть;

- возможность коммуникации и обмена данными с технологическим оборудованием, установками;

- обработка полученной информации и отправка команд в реальном времени;

- отображение полученной информации в графической форме (мнемосхемы, графики, таблицы);

- функции оповещения о предаварийных, аварийных событиях, выходе параметров установок из нормального рабочего режима;

- сохранение, архивирование информации в базе данных;

- периодическое генерирование и подготовка отчетов о работе технологического оборудования и систем;

- отсутствие или минимальные вложения материальных и финансовых средств.

- В качестве параметров мониторинга предлагается:

1. Параметры серверного оборудования:

- доступность самого сервера;

- список оборудования сервера;

- характеристики оборудования сервера;

- загруженность процессора сервера;

- температура процессора сервера;

- свободный объемоперативной памяти;

- использование виртуальной памяти (файла подкачки), если она есть;

- свободное место на дисковых массивах;

- состояниедисковых массивов: состояние каждого отдельного массива и SMART каждого диска;

- нагрузка на сетевые интерфейсы;

- список запущенных процессов;

- список процессов, которые больше потребляют ресурсов процессора; 
- список процессов, которые больше потребляют ресурсов оперативной памяти;

- список процессов, которые больше потребляют ресурсов сетевых интерфейсов;

- список установленного ПО.

2. Сетевое оборудование:

- доступность коммутатора;

- температура коммутатора;

- свободный объем оперативной памяти коммутатора;

- загруженность процессора коммутатора;

- количество отправленныхbroadcast пакетов;

- количество принятыхbroadcast пакетов;

- количество отправленныхmulticast пакетов;

- количество принятых multicast пакетов;

- количество отправленныхunicast пакетов;

- количество принятыхunicast пакетов;

- количество ошибок при отправке;

- количество ошибок при получении;

- очередь пакетов;

- состояние портов;

- список портов, на которые приходится наибольшая нагрузка.

3. Источник бесперебойного питания:

- входное напряжение;

- выходное напряжение;

- частота входного напряжения;

- температура ИБП;

- нагрузка на ИБП;

- заряд батарей ИБП;

- напряжение батарей ИБП;

- исправность батарей;

- количество подключенных блоков батарей.

4. Программное обеспечение: 
- общий список ПО в ИВС центра обработки данных;

- список программного обеспечения на каждом сервере;

- список всех лицензий ПО в ИВС;

- контрольза использованием лицензий в ИВС;

- мониторинг изменения ПО в ИВС;

- контроль за изменением ПО на каждом сервере.

Мониторинг состояния оборудования и программного обеспечения позволит предвидеть возможные аварийные ситуации и заранее предупредить их развитие. Централизованная система позволяет свести все системы в единое целое и получить объективную картину того, что происходит в различных системах ЦОД. 